DOSSIÊ TEMÁTICO: Educação Inclusiva e Processos de Subjetivação

d० https://doi.org/10.22481/praxisedu.v16i37.5981

\title{
ENTRE CARTAS E CONVERSAÇÕES: ENCONTROS NA DIFERENÇA
}

BETWEEN LETTERS AND CONVERSATIONS: MEETINGS IN DIFFERENCE

ENTRE ENTRE CARTAS Y CONVERSACIONES: ENCUENTROS EN LA DIFERENCIA

Daiana Pilar Andrade de Freitas Silva

Faculdade de Formação de Professores da Universidade do Estado do Rio de Janeiro - Brasil

Instituto Benjamin Constant - Brasil

Anelice Ribetto

Faculdade de Formação de Professores da Universidade do Estado do Rio de Janeiro - Brasil

Resumo: Este ensaio é um desdobramento de uma tese produzida em uma universidade pública brasileira. Trata-se de um exercício cartográfico, que no processo foi ganhando forma ensaística. Um trabalho no qual buscamos problematizar os efeitos dos encontros entre uma professora e crianças com cegueira, entendendo que o pesquisar e escrever não se separam: portanto uma pesquisaescrita. Colocamos em questão não só a narrativa dos efeitos produzidos nos encontros, mas também os modos como as políticas da narratividade -dominantes e majoritárias- impõem determinadas formas de pesquisar e escrever e excluem outras, formas estas que em sua maioria limitam o educar a um processo que se dá muito mais entre iguais do que sendo uma relação que tem como potencial a diferença. Assim, buscamos pensar a tese produzida como uma experiência na diferença, em que modos outros de narrar são necessários para explicitar o encontro entre nós.

Palavras-chave: Cegueira. Diferença. Encontro.

\begin{abstract}
This essay is an offshoot of a thesis produced in a Brazilian public university. It is a cartographic exercise, which in the process was gaining essay form. A work in which we seek to problematize the effects of encounters between a teacher and children with blindness, understanding that research and writing do not separate: therefore a writtenresearch. We question not only the narrative of the effects produced in the encounters, but also the ways in which the dominant and dominant policies of narrativity impose certain forms of research and writing and exclude others, forms that mostly limit educating to one process that is much more between equals than being a relationship that has the potential for difference. Thus, we seek to think of the thesis produced as an experience in difference, in which other ways of narrating are necessary to make explicit the encounter between us.
\end{abstract}

Keywords: Blindness. Difference. Meeting.

Resumen: Este ensayo es una rama de una tesis producida en una universidad pública brasileña. Es un ejercicio cartográfico, que en el proceso fue ganando forma de ensayo. Un trabajo en el que buscamos problematizar los efectos de los encuentros entre un maestro y niños con ceguera, entendiendo que la investigación y la escritura no se separan: por lo tanto, una investigaciónescrita. Cuestionamos no solo 
la narrativa de los efectos producidos en los encuentros, sino también las formas en que las políticas dominantes y la narrativa mayoritaria se imponen en ciertas formas de investigación y escritura y excluyen otras. eso es mucho más entre iguales que ser una relación que tiene el potencial de diferencia. De esta manera, buscamos pensar la tesis producida como una experiencia en la diferencia, en que modos otros de narrar son necessarios para explicitar el encuentro entre nosotros.

Palabras clave: Ceguera. Diferencia. Encuentro.

\section{Uma abertura...ou uma introdução}

Encontrar é descobrir, capturar, roubar. Mas não há um método para descobrir, apenas uma longa preparação. Roubar é o contrário de plagiar, de copiar, de imitar ou fazer como. A captura é sempre uma dupla captura, o roubo, um duplo roubo. É assim que se cria, não algo de mútuo, mas um bloco assimétrico, uma evolução a-paralela, núpcias, sempre $\langle<$ fora $\rangle\rangle \mathrm{e}<\langle$ entre $\rangle$. Uma conversa seria precisamente isso (DELEUZE; PARNET, 2004, p.17).

Os encontros expressam em si a dimensão da conversa, pois é no encontro que a conversa se produz enquanto possibilidade de problematizar, de formular nossas próprias questões. É em meio ao encontro que se pode conversar e a conversa carrega em si a arte de problematizar, nos permitindo fabricar outras questões. Para os autores citados, quando não há essa possibilidade de fabricar as próprias questões, ou seja, quando as questões nos são dadas não temos muito a dizer, portanto, não há conversa.

Este ensaio se enuncia como um desdobramento de muitos encontros, nos quais entramos ao longo da produção de uma tese, junto aos encontros semanais com um coletivo, que reúne professores da escola básica, professores e estudantes, gestores das redes públicas de ensino e famílias de alunos ditos "pessoas com deficiências". Neste coletivo desenvolvemos projetos de pesquisa, de ensino e de extensão, e pensamos também nos modos de narrar os efeitos dos encontros que tem como potência a diferença, assim conversamos.

As conversas possibilitaram a produção de uma tese orientada em uma universidade pública brasileira. Assim, colocamos em questão a experiência de produção da tese que problematiza os efeitos dos encontros com crianças com cegueira, estudantes de uma escola especializada e, também, a necessidade de um pesquisarescrever outro que nos permita explicitar o que nos passa, nos encontros, nas conversas: na diferença. Trata-se de uma conversa interrompida por outras conversas, que talvez possa nos permitir outras interrupções, onde outros sujeitos possam entrar e, nós mesmos, continuarmos a transitar de modos outros, imprevisíveis. 
Por isso entendemos esta introdução, "Uma abertura...ou uma introdução", como uma possibilidade de abertura ao encontro, que talvez este ensaio nos permita. Seguimos neste ensaio com "Uma tese... uma composição outra", em que contextualizamos o trabalho que foi desenvolvido na tese, explicitando sua organização e a metodologia enunciada em sua composição. Posteriormente apresentamos "Uma carta: eu sou especial”, "Uma conversação: palavras e efeitos", "Outra carta: um silêncio que fala" e "Outra conversação: educar também é estranhar" a fim de dar a ver a potência do encontro, entre uma professora e crianças com cegueira, encontro este que só se materializa na diferença. As cartas e as conversações apresentadas aqui foram mantidas no tempo verbal em que aparecem no texto da tese, se mantendo o formato original. Para enfim finalizarmos com "Um fechamento...ou considerações finais".

\section{Uma tese... uma composição outra}

A tese produzida ao longo dos dois anos de mestrado nos permitiu pensar no encontro, na diferença, na amizade, e também questionar o modo como o qual escolhemos para narrar o que nos passa no campo educacional, sem perder de vista a potência do encontro que se dá na diferença, e não entre iguais. Sentimos também a necessidade de buscar formas de narrar que contemplasse a heterogeneidade da relação educacional, tendo em vista uma tendência, no campo acadêmico ao igual, legitimando-se formas homogêneas de escrita.

A metodologia que se enunciou na produção da tese, foi pensada como um exercício cartográfico. A cartografia nos permite acompanhar um processo e criar formas de dizer, narrar, expressar os efeitos dos encontros entre nós. "O Cartógrafo é um verdadeiro antropófago: vive de expropriar, se apropriar, devorar e desovar, transvalorado. Está sempre buscando elementos/alimentos para compor suas cartografias" (ROLNIK, 1989, p.2). Desta forma, o exercício cartográfico foi se compondo de modo processual, no encontro com o campo de pesquisa, com as crianças com cegueira, nas conversas com os autores e nos encontros com o coletivo.

A processualidade se faz presente nos avanços e nas paradas, em campo, em letras e linhas, na escrita [pesquisaescrita] em nós. A cartografia parte do reconhecimento de que o tempo todo, estamos em processos, em obra. $\mathrm{O}$ acompanhamento de tais processos depende de uma atitude, de um ethos, e não está garantida de antemão (BARROS; KASTRUP, 2009, p. 73). 
A atitude, forma de ser e se colocar eticamente na pesquisaescrita, nos permitiu estar disponível para pensar seu contorno metodológico e escriturístico, que se traduziu como um ensaio. O ensaio como efeito do próprio exercício cartográfico e que também tem a ver com a experiência literária que se forja nos encontros com crianças com cegueira. Um ensaio composto em cartas a uma amiga e conversações. Uma experiência modificadora de si.

Pode se dizer, talvez, que o ensaio é uma atitude existencial, um modo de lidar com a realidade, uma maneira de habitar o mundo, mais do que um gênero de escrita. Pode se dizer, talvez, que o ensaio é o escrito precipitado de uma atitude existencial que obviamente, mostra enormes variações históricas, contextuais e, portanto, subjetivas. Pode-se dizer, talvez, que o ensaio é uma determinada operação no pensamento, na escrita e na vida, que se realiza de diferentes modos em diferentes épocas, em diferentes contextos e por diferentes pessoas. Pode-se-ia dizer, talvez, que o ensaio é o modo experimental do pensamento, o modo experimental de uma escrita que ainda pretende ser uma escrita pensante, pensativa, que ainda se produz como uma escrita que dá o que pensar; e o modo experimental, por último da vida, de uma forma de vida que não renuncia a uma constante reflexão sobre si mesma, a uma pensante metamorfose. (LARROSA, 2004, p. 32).

O ensaiar permite desnaturalizar, estranhar o presente e é esse movimento que produz o deslocamento daquilo que já está dado, do instituído, para pensar sob outras perspectivas. Desta forma, apresentamos uma pesquisaescrita organizada de um modo outro: entre cartas a uma amiga e conversações que anunciam sentimentos e pensamentos, experienciados nos movimentos da vida. O modo como a tese foi composta diz respeito a uma tomada de posição onde nos colocamos politicamente implicadas. Assim, na experiência da pesquisaescrita transitam algumas cartas escritas a uma amiga, e também outras conversações. Ambas, produzidas em meio ao desejo pelos encontros. "É no encontro, nesse meio de proliferação, que os corpos expressam sua potência de afetar e ser afetado. É nele que o desejar flui e cria mundos agenciando modos de expressão e a conectividade da vida em suas múltiplas experimentações" (NEVES, p. 69, 2015).

Assim, nos encontramos com a escrita, com a relação de amizade, com um coletivo, com autores, territórios, crianças com cegueira e, também, com os efeitos provocados nos próprios pensamentos. As cartas a uma amiga expressam a experiência com outros, no território escolar, onde narramos os pensamentos e inquietações que os encontros provocam. Elas se apresentam na pesquisa como dispositivos que, segundo Deleuze (1996) são “máquinas de fazer ver e de fazer falar" (p.83). Os dispositivos são:

[...] um conjunto decididamente heterogêneo que engloba discursos, instituições, organizações arquitetônicas, decisões regulamentares, leis, 
medidas administrativas, enunciados científicos, proposições filosóficas, morais, filantrópicas. Em suma, o dito e o não dito são os elementos do dispositivo. O dispositivo é a rede que se pode estabelecer entre esses elementos. (FOUCAULT, 1979, p.244).

A carta assumida como um dispositivo que carrega no papel aquilo que fazemos em nosso cotidiano: as conversas, os encontros... Para além disso, carrega ainda, a expressão do dito e o do não dito, a relação que se pode estabelecer entre esses elementos e os efeitos produzidos no campo de pesquisaescrita e seu próprio movimento.

Ao trazer cartas a uma amiga na produção do texto pensamos nelas como aliadas no processo de criação, implicando-nos na pesquisaescrita e no acompanhamento de seus efeitos. Efeitos expressados no processo de produção da pesquisaescrita e também na produção da materialidade do papel em que foram escritas as cartas a uma amiga que expressa, também, o modo ensaístico e artesanal em que a pesquisaescrita foi composta.

O ensaio permite uma escrita de cacos. Cacos [sobras] do que se partiu, cacos [sobras] do que foi jogado fora, do que foi abandonado, do que foi substituído por uma moda ou pela gulodice de um consumo desmesurado. Cacos [sobras] que podem ser reutilizados, recuperados para emergir em outra coisa. (RIBETTO,2009, p.22).

Nesse sentido, para escrita das cartas a uma amiga, foi produzido um papel reutilizado, feito pelos restos, produzido pelas sobras dessa pesquisaescrita que, ao serem recuperados se transformaram em outra coisa, tornando-se outro. Ou seja: no decorrer do processo da pesquisaescrita fomos escrevendo, rascunhando, delineando em cadernetas, guardanapos, papeis de chocolates, folhas soltas, imprimindo um monte de textos nas diferentes disciplinas cursadas etc. Isso tudo não foi jogado fora como um resto improdutivo mas, ao contrário, ao misturar esses cacos ou restos de papéis, com água, foi deixado de molho de modo a se decompor, utilizamos uma tela para nova composição e, assim, foi reinventado o material em que as cartas para uma amiga foram escritas. Esse investimento como um gesto de quem faz alquimia constitui uma expressão do que política, ética e esteticamente desejamos forjar a partir da pesquisaescrita. Assim como nos coloca Dias (2016):

Ético, porque abre-se à possibilidade de fazer escolhas, produzindo desmanchamentos de formas dadas. Estético porque faculta a criação de uma vida bela e livre nas ligas da constituição de uma arte, pelo plano dos afetos e perceptos. Político porque desejamos forjar encontros e poder tecer uma conversa para talvez, enfrentar o desafio de formar e pesquisar mantendo vivo um campo problemático, apostando na condição e possibilidade de diferir do que somos. (p.118). 
No sentido de potencializar essa possibilidade de diferir do que somos que as cartas foram endereçadas a uma amiga. São cartas que não estabelecem em si uma relação de correspondência de ida e volta, mas nos permite pensar na amizade como relação de alteridade, uma relação ética. Ao direcionar as cartas a uma amiga problematizamos a própria relação de amizade, colocando-a como máxima expressão da diferença. Relação livre "que aponta para o desafio e para incitação recíproca e não para submissão ao outro" (ORTEGA,1999, p.168), portanto, possível de romper com modelos pré-estabelecidos.

Nas conversações buscamos nos encontrar com outros interlocutores, como autores, textos, obras de arte, entre outros, para problematizar questões do campo de pesquisa que se enunciaram nas cartas a uma amiga. Incluem justamente a problematização das cartas a uma amiga compostas pelos efeitos dos encontros com crianças com cegueira. Poderíamos dialogar, mas prefiro conversar, por acreditar, assim como Skliar (2017), que existe uma diferença abismal entre o diálogo e a conversação. O autor coloca que o diálogo se realiza segundo a vontade de quem o convoca. Em contrapartida, conversar trata-se de um gesto diferente, isto é, "um encuentro sin princípio ni fin que se desvía, avanza y retrocede, se pierde y quizá se reencuentra” (SKLIAR, 2017, p.173). A conversação é uma palavra que não rebaixa e nem diminui, não supõe superioridade e inferioridade e sim sugere horizontalidade, oralidade e experiência, nos permitindo sentir juntos (LARROSA, 2013).

A conversa tem a ver com a diferença e não com ideia de fraternidade. Desse modo, vai de encontro ao que afirma a amizade como relação que comporta a diferença e não como relação fraterna que se dá entre iguais.

[...] o valor de uma conversa não está no fato de que ao final se chegue ou não a um acordo...pelo contrário, uma conversa está cheia de diferenças e a arte da conversa consiste em sustentar a tensão entre as diferenças... mantendo-as e não as dissolvendo... e mantendo também as dúvidas, as perplexidades, as interrogações...e isso é o que a faz interessante... por isso em uma conversa não existe nunca a última palavra... por isso uma conversa pode manter as dúvidas até o final, porém cada vez mais precisas, mais elaboradas, mais inteligentes...por isso uma conversa pode manter as diferenças até o final, porém cada vez mais afinadas, mais sensíveis, mais conscientes de si mesmas... por isso uma conversa não termina, se interrompe... e muda para outra coisa... (LARROSA,2003, p.212).

Dando continuidade a esta conversa apresentamos um recorte de duas cartas e duas conversações que fazem parte do texto apresentado neste ensaio, que talvez nos sirva para pensar na relação educativa em sua potência de diferir. 


\section{Uma carta: eu sou especial}

Rio de janeiro, 21 de novembro de 2017.

Querida amiga,

Estou sentada aqui por entre as árvores da Praça do Ledor. Considero esse lugar especial, venho aqui para ler, para pensar, para fazer nada, e também é aqui que costumo escrever para ti, para mim e para outros, às vezes me arrisco a uma poesia ou outra.

Hoje tivemos uma manhã chuvosa, poucos alunos vieram, da minha turma apenas Lucas. Pensei em não contar a história que havia separado, mas logo voltei atrás ao ouvi-lo:

- Tia, hoje é dia de roda de leitura né?

Lembrei-me logo da fala de sua mãe na entrada informando-me que não iria levá-lo por conta da chuva, mas ele disse que era dia de história e não podia faltar. Logo o respondi.

- Sim Lucas. Hoje é o dia.

E, assim nos sentamos, ele e eu, próximos à janela envolvidos pelo som da água que após se encontrar com as folhas das árvores caía em pingos ao chão, nos permitindo também sentir um cheirinho maravilhoso da terra molhada.

Em meio a esses sentidos abri o livro "A maior flor do mundo" de José Saramago (2001). O autor se faz personagem para questionar sua capacidade em escrever para crianças visto que, para ele, as histórias infantis devem ser escritas com palavras bem simples, por isso que gostaria muito de saber escrever com essas palavras. Depois se arrisca contando a história de um menino que morava numa aldeia e que um dia ao brincar teve a oportunidade de ultrapassar os limites geográficos daquela aldeia a ponto de ficar no impasse de ir ou não ir e foi. No limite do caminho encontrou uma flor murcha voltou em busca de água para flor e encontrou em um rio distante, não havia um recipiente para colocar a água, assim encheu suas mãos e levou a água para a flor, mas era pouco e ficou a buscar água por 20 vezes. Muito cansado, dormiu ao lado daquela flor que, ao ser molhada, cresceu e abrigou a sombra aquele menino... a flor era tão grande que da aldeia podia ser vista e foi assim que os pais do menino o encontraram ao abrigo de uma pétala.

Depois da história ficamos conversando sobre a atitude do menino. Lucas me disse que o menino ficou cansado, pois foi 20 vezes pegar água longe. Diante dessa fala eu o perguntei:

- Por que será que ele fez isso, né?

Ficamos por alguns minutos em silêncio ao ouvir somente o som que vinha de lá de fora. Achei que não ouviria nenhuma resposta a minha pergunta, mas, de repente o silêncio foi interrompido e Lucas me respondeu:

- Tia ele fez isso porque ama a flor. A gente só faz isso quando ama. Você me ama?

- Te amo sim.

Ele, inquieto, talvez com minha resposta curta, pergunta:

- Por que você me ama?

Não esperava tal pergunta e para respondê-lo recorri ao uso de alguns adjetivos e disse: 
- Porque sou sua professora e você é um menino, inteligente, agradável, gosta de conversar... enfim você é um menino especial.

Ele demonstrou-se feliz ao ouvir cada adjetivo. Mas quando ouviu a palavra especial não pensou duas vezes e logo me respondeu:

- Você não pode me amar porque sou especial, eu sou especial, mas eu sei fazer outras coisas.

Foi nesse momento que me dei por conta dos usos e sentidos da palavra "especial" e percebi que havia ali entre meu aluno e eu, um estranhamento que me permitiu sair da zona de conforto em que estava. Um estranhamento carregado por outras perguntas que rapidamente passaram pela minha cabeça: O que é ser especial? Quais os sentidos desta palavra? Eu a usei para dizer que o fato de ser inteligente, agradável gostar de conversar o tornava notável, isto era o especial para mim ali, naquele momento. E nesse movimento de segundos perguntei:

- o que é ser especial para você?

Ele respondeu:

- Sei que não enxergo, por isso falam que sou especial, mas eu sou muito inteligente eu sei fazer outras coisas.

Logo me expliquei perguntando para ele o que era uma manga, rapidinho ele respondeu:

- É uma fruta!

Uma fruta também. Mas isso que cobre seu ombro e faz parte da sua camisa também se chama manga. As palavras são assim às vezes são iguais, mas querem dizer coisas diferentes. Quando eu falo que você é especial para mim é pelo fato de você gostar de conversar, e eu também, gostar de histórias etc. Ele sorriu e disse:

- É mesmo!

Depois da conversa fiquei inquieta pensando sobre o que as palavras fazem com a gente? Os sentidos que elas podem carregar? A situação me fez até entender o porquê que Saramago, personagem da história que contei, acha que as histórias para crianças devem ser escritas com palavras simples, pois há crianças não gostam de perder tempo com palavras complicadas. Por que complicamos as palavras? Afinal, o que está dentro da palavra especial?

Em breve the conto mais, Abraços.

\section{Uma conversação: palavras e efeitos}

Estranho esse tremor ao experimentar sensivelmente as palavras. Esperar que talvez, algum dia, um pensamento, vindo de não sabe onde, se deixe surpreender numa frase, vinda de não se sabe o quê. Ou ao contrário. E vivêlo. E escrevê-lo. Estranha forma de amor, de amizade (LARROSA, 2012, p.9).

A palavra especial ocupou por algum tempo meus pensamentos. Recorri a um dicionário na busca por sua definição. Individual, particular, próprio, peculiar, específico, típico, exclusivo, privativo, reservado, etc., foram algumas das definições que encontrei. Fechei. O movimento de buscar um significado no dicionário provocou em mim um estranhamento, um 
vácuo, um vazio, como se as palavras estivessem ali, mas ao mesmo tempo não me dissessem nada, ou dissessem o nada. O nada, o vácuo, o vazio também são formas de dizer. "E ao fechar o dicionário, começa uma rebelião da palavra, a dança da palavra, a abertura infinita da palavra" (SKLIAR, 2012, p. 37). Assim, me lembrei do livro "Experiências com a palavra: notas sobre linguagem e diferença” de Carlos Skliar (2012), já havia lido em 2017, mas o desejo pela palavra me permitiu abri-lo novamente. Sabia que ali não encontraria nenhuma definição, mas o movimento já não era por uma definição, mas pelas palavras e seus efeitos. Para Skliar (2012):

Não existe dicionário que possa ser aquilo que foi, é e será a palavra. No dicionário, a palavra é um dever ser antológico. Nele repousam somente os restos aparentes das palavras, sua estática languidez, sua verdade sempre trêmula e aterrorizada. Ali se fixa só o duplo virtual da palavra, a virtualidade do que dizer ante nenhum rosto, a virtualidade do que quer dizer dizer.(...) Por isso, não se há de buscar no dicionário aquilo que não se buscou na vida. Não se há de encontrar no dicionário aquilo que não se encontrou na vida. Não se há de saber no dicionário aquilo que não se soube na vida. (p. 37).

Desse modo, talvez, possamos pensar em dicionários que nos mostrem não um sentido único e restrito de uma palavra, mas sim que tenha a ver com as sensações, com a vida e menos com significados, como o fez Ambrose Bierce (2016), em "Dicionário do Diabo", ao subverter o sentido habitualmente atribuído às palavras, dando-as outros sentidos, mais ligados às sensações, o autor assume um papel de diabo ao inventar um dicionário politicamente incorreto, que foge da lógica dos significados, um dicionário que tem mais a ver com os efeitos, algo que nos permite a possibilidade de pensar, buscar outros sentidos. Acredito como Skliar na impossibilidade de se descobrir apenas nos dicionários convencionais aquilo que não se descobriu na vida. Mais do que os significados, são os sentidos e efeitos, as experiências com as palavras. Isso não se encontra em dicionários. A palavra tem disso, pode nos provocar, nos deixar sem palavras, fazer pensar as palavras.

Palavras que, como tantas outras, talvez possam deixar a marca e vacuidade das palavras, incorporar outros corpos, decompor o próprio pensamento, fazer-nos olhar o olhar, intuir a poética que é do outro, desmesurar o tempo, contradizer o dito (e vice-versa), adiar a morte. (SKLIAR, 2012, p. 17).

No exercício de olhar o olhar, decompor o pensamento, sentir a marca e vacuidade da palavra, me desencontrei. Foi nesse momento que me dei por conta dos usos e sentidos da palavra "especial" e percebi que havia ali entre meu aluno e eu, um estranhamento que me permitiu sair da zona de conforto em que estava (parte da carta “... eu sou especial...”). Segundo Skliar (2012) toda palavra se torna presente a partir do momento em que o ser se desencontra. 
Assim pude pensar na palavra especial, pude estranhar sair da zona de conforto, me desencontrar. Um desencontro produzido pelo encontro entre o sentido que atribui para a palavra e o sentido atribuído por meu aluno. Nesse movimento sou afetada pelos efeitos do encontro e desencontro, vou alimentando minhas inquietações, assim como o menino, personagem da história de Saramago alimenta a flor.

Penso, ainda, em nossas falas expressadas na carta “... eu sou especial...”:

-(...) sou sua professora e você é um menino, inteligente, agradável, gosta de conversar... enfim você é um menino especial.

(...)

- Sei que não enxergo, por isso falam que sou especial, mas eu sou muito inteligente eu sei fazer outras coisas.

Percebo que nosso encontro foi atravessado pela palavra especial: de um lado a ideia de destaque que indica presença e do outro a ideia de falta que indica ausência. Penso ao problematizar minha fala que talvez não precisasse de um "enfim você é especial", é como se o ser inteligente, agradável etc., não me bastasse. Por que precisei de um enfim? Problematizo também o fato do meu aluno ainda criança já sentir essa necessidade de justificar sua condição, entendida do ponto de vista biológico como uma falta, evidenciando sua inteligência e o fato de saber outras coisas. Talvez ambos, meu aluno e eu, naquele momento estivéssemos marcados pela ideia da palavra, essa que encontramos nos dicionários, ou que nos são transmitidas por meio dos discursos.

Lembro-me das palavras de Charles Chaplin no filme "O grande ditador" quando disse que "pensamos muito e sentimos pouco" (1940), pensamos no sentido de termos muitas ideias, pois Chaplin se referia as máquinas às tecnologias das fábricas, eu diria que idealizamos muito e sentimos pouco. Aqui eu me refiro à necessidade de sentirmos mais as palavras, visto que são muitos os significados que elas podem nos transmitir, mas precisamos sentir. E o sentir não está no dicionário e nem nos discursos homogêneos, mas na vida, no encontro, precisamos viver a palavra, sem se esconder de seus efeitos. "A cada pronunciação fazemos e nos fazem algo com a palavra: amamos e odiamos, escapamos e voltamos ficamos em silencio e fugirmos, destroçados do silêncio" (SKLIAR, 2012, p. 36).

Talvez a simplicidade a qual Saramago se refere em "A maior flor do mundo" quando diz que as histórias para crianças devem ser escritas com palavras simples, pois a crianças não gostam de perder tempo com palavras complicadas (parte da carta (carta “... eu sou especial...”), diga respeito justamente aos efeitos e não aos significados. Temos limitado muito as palavras 
atribuindo-as significados, isto é, complicado muito as palavras. Simplificar, talvez exija uma mudança do olhar, “... isto é, voltar o olhar mais para a literatura do que para os dicionários, mais para os rostos do que para as pronuncias, mais para o inominável do que para o nominado" (SKLIAR, 2003, p. 20). Talvez, ainda, na simplicidade das palavras possamos encontrar sua marca e vacuidade, sua profundidade, seus vazios...

E experimentando as palavras, seja no encontro, nas leituras, com Skliar, Larrosa, Saramago e Chaplin, sigo com as palavras de Larrosa: "Estranho, esse ofício de experimentar palavras." (LARROSA, 2012, p. 9).

\title{
Outra carta: um silêncio que fala
}

\author{
Rio de janeiro, 05 de julho de 2018.
}

\section{Querida amiga,}

Gostaria de compartilhar contigo meus silêncios, um provocado por uma dor momentânea e outro pelo pensar que tem permitido expressar-me nestas palavras que lhe escrevo. Problematizo o quão estranho é essa arte de conviver, de ensinar, aprender, nos encontrar, educar. Penso que não se trata de uma relação harmônica como muitos sugerem ser. Mas vamos ao primeiro silêncio que invadiu o nosso encontro desta manhã de quinta-feira: estávamos meus alunos e eu, separei um dito clássico da literatura infantil "Cachinhos dourados". A ideia era explorar a história com os sons, os objetos. Para tal achei interessante levar alguns itens que aparecem na história, tais como panelas, colheres de pau, pratos de diversos tamanhos, entre outros. Estavam todos participativos, fizemos os passos de cachinhos caminhando sobre as folhas secas da floresta... etc. Em meio a história, ao manusearmos as colheres e a panela para o mingau, me distrai e uma das crianças ao movimentar a colher me deu, obvio que sem intenção, uma colherada nos lábios. Na hora um silêncio tomou conta da sala, meus olhos se encheram de água, me segurei para não chorar, não queria preocupá-los, todos ficaram quietos como se o silêncio ali naquele momento fosse uma regra. Ninguém falava nada. Com o lábio inferior inchado, precisei me ausentar da sala, quando, retornei todos preocupados queriam saber se eu estava bem. Ai sim, expliquei o ocorrido e conversamos sobre. Meu lábio, ainda inchado, virou motivo de pesquisa... ficamos ali conversando e o final da história deixamos para outro dia. Depois do nosso encontro fiquei em silêncio, não mais provocado pela dor, mas agora pelo meu pensar. Algo naquele silêncio do momento em que fui atingida me chamou atenção, sabe, estou pensando nas nossas relações, nos estranhamentos, no educar. Talvez educar e aprender seja isso: estranhar. Neste caso, o imprevisto físico é apenas uma brecha que me serve de alavanca para problematizar essa imprevisibilidade do encontro com o outro. O silêncio provocou-me o pensamento. E nesse movimento o meu pensar segue em direção as relações, ao saber, a aprendizagem, a educação como um acontecimento passível 


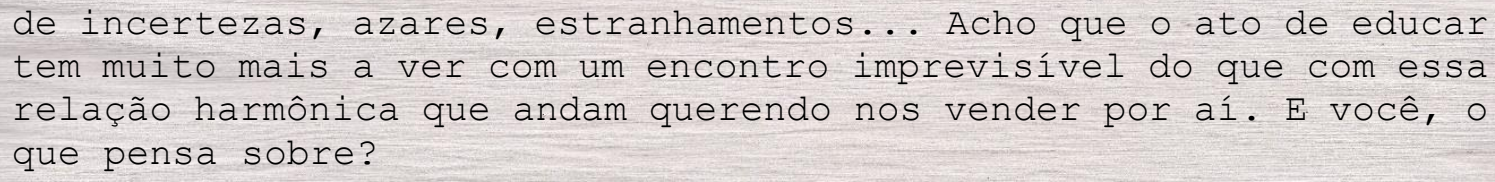

Um abraço.

\section{Outra conversação: educar também é estranhar}

[...] callar es sintoma de una prudente distancia con lo que ocurre alrededor; algo así como omitirse del mundo para pensar el mundo, algo así como suspenderse en la altura para luego, más tarde, recomponer em palavras el barulho incesante e imcompresible del universo. (SKLIAR, 2011, p. 338).

No silêncio, inicialmente provocado por uma dor física que senti, pensei problematizei e busquei palavras que dessem conta de conversar sobre minhas inquietações. Clarice Lispector (1968), em Crônicas ao Jornal do Brasil disse: "Há um grande silêncio dentro de mim. E esse silêncio tem sido a fonte de minhas palavras", talvez seja assim, o silêncio tenha sido fonte de minhas palavras, no silêncio problematizo e busco palavras para pensar a educação como um encontro, um encontro ético, vivido, que inclui incertezas, estranhamentos, dúvidas, alegrias e tristezas. Ao dividir com as crianças o que me passa, os acontecimentos do dia a dia, escutá-los e senti-los vou me tornando outra, afinal tantas coisas têm acontecido quando nos encontramos, ao nos relacionarmos, quantas aprendizagens. Talvez o educar tenha muito a ver com isso, um encontrar-se eticamente, isto é aberta, sensível as alegrias, sofrimentos, etc. Assim vamos aprendendo, e o aprender ao qual me refiro aqui "es aprender a decifrar los signos que se desparraman a lo largo de la vida e que están en cualquier sitio. A cualquier hora. En cualquier texto. Incluso en el silencio. También en la escuela (SKLIAR, 2011, p. 132).

Penso na convivência educativa enquanto espaço e tempo de encontro, em que estamos juntos e fazemos coisas juntos e fazer coisas juntos não demanda necessariamente uma relação harmônica, ao contrário, trata-se de um espaço de incertezas, estranhamentos, descobrimento das fragilidades, etc.

Así, el "estar juntos" no supone um valor intriseco o una virtud em si misma: se trataria más bien de una descripción- más que de una definición- sobre ló que ocurre em la cotidianidade de las comunidades, matizada no solo por la potencia del encuentro no la capacidad de desarrollar un proyecto comun, sino tambien por la impotencia, por el desencuentro, en fin, por el descubrimiento de las mutuas fragilidades. (SKLIAR, 2017, p.75).

Skliar nos permite pensar na impossibilidade de sustentar a ideia de que as relações no espaço escolar acontecem, ou devem acontecer de forma harmônica, visto que o "estar juntos" 
não se trata apenas de se estar próximos em concordância, mas sim envolve conflitos, discordâncias, dificuldades para conversar, para compreender, etc. No encontro que cito na carta não havia pensado na possibilidade de levar uma colherada na boca, trata-se de um ocorrido imprevisível, mas que aqui me serve para pensar justamente nos desencontros, nos estranhamentos que também estão presentes nesse processo educacional, nem sempre marcados por ações visíveis como foi o caso.

Los encuentros que nos recomponen en la diferencia, en la relación de alteridad, no son previstos ni programables sino inesperados, porque se dan en medio del azar y ellos mismos son azar. Se dan con tensiones que generan el movimiento mismo de recomposición de los cuerpos y, en estas tensiones, lo que hemos de procurar es resistir a las fuerzas que debilitan nuestra potencia de hacer cosas por la vida, la propia y la de otros, tanto como dirigir nuestros esfuerzos a la composición de un cuerpo más alegre y más potente en los encuentros que propician la creación de nuevas formas de vivir en común exponiéndonos al otro de la diferencia. (SKLIAR; TÉLLEZ, 2017, p. 130).

Skliar e Téllez (2017) colocam a necessidade de um outro modo de exercer a educação, de forma a romper com as práticas dominantes que são realizadas sob a luz de um modelo preestabelecido, que tem mais a ver com o preparo, com métodos, que buscam resultados. Esse outro modo de educar está ligado à possibilidade de crítica e criação, um educar sem receitas, sem regras pré-estabelecidas, onde as perguntas não tenham respostas a priori, mas possibilitem o pensamento, "amando el movimiento de aprender em encuentros a-pares" (SKLIAR; TÉLLEZ, 2017, p. 45).

O fato de pensar a educação sem modelos preestabelecidos não significa não planejar, não desejar. Na carta esse movimento fica claro quando digo: Meu lábio ainda inchado virou motivo de pesquisa... Ficamos ali conversando e o final da história deixamos para outro dia. Poderia ter dado continuidade a história que havia planejado, mas naquele momento não achei pertinente ignorar o que havia acontecido e assim meu lábio machucado passou a ser o tema de nosso encontro. Ao longo dos encontros entre nós muitas coisas planejei e desejei para nós, e não aconteceram, outras aconteceram e ainda outras que só passaram a fazer parte do registro dos meus desejos depois que acontecerem. Nesses movimentos entre silêncios, palavras, incertezas, alegrias e tristeza, ensinamos e aprendemos.

Nunca se sabe de antemão como alguém vai aprender - que amores tornam alguém bom em Latim, por meio de que encontros se é filósofo, em que dicionários se aprende a pensar -. Os limites das faculdades se encaixam uns nos outros sob a forma quebrada daquilo que traz e transmite a diferença. Não há método para encontrar tesouros nem para aprender... (DELEUZE, 2006, p.159). 
Nesse sentido que tenho pensado o educar, o aprender, o ensinar, o torna-se professor, estudante, etc., como práticas imprevisíveis, passíveis também de estranhamentos. Trata-se de uma relação habitada por sentidos, efeitos que se produzem numa dimensão ética que tem no encontro na alteridade sua potência. A relação educativa, talvez tenha mais a ver com esses movimentos de estranhamentos, e menos a ver com os métodos ou receitas predefinidos, talvez precisemos, como inicio, apenas da presença do outro, da diferença, dos silêncios produzidos entre nós, nas incertezas, nas ausências das palavras...

\section{Um fechamento...ou considerações finais}

O sentido do ensaio aqui apresentado tem muito a ver com o imprevisto, com as incertezas que se materializam no encontro, no diferir. Acreditamos ser esta uma possibilidade que nos ajude a pensar algumas questões que atravessam o campo educacional, direcionando o nosso olhar para a diferença, enquanto relação que carrega em si a potência do encontro.

El encuentro es con lo inesperado que se mueve hacia outra parte, con lo que difere de uno, de otro y de ambos; una diferencia que habita entre la planificación y la conmoción, entre lo previsible y el acontecimento, ese espacio indefinible de la contigencia donde tudo puede ocurrir. (SKLIAR, 2015, p.34).

Assim sentimos a necessidade de modos outros de narrar, que comporte o encontro na diferença. Nesse sentido que produzimos a tese que foi apresentada neste ensaio e defendemos a necessidade de um olhar outro no campo educacional a respeito da diferença. Tendo em vista que se trata de um campo marcado por olhar a diferença enquanto desvio, oposição e desigualdade. Modos estes de olhar que tendem a desconsiderar a potência do encontro na educação, pois classificam e categorizam os sujeitos.

Ao apresentar uma tese organizada de modo outro que difere do que estamos acostumados a ver no campo acadêmico, se buscou não só dar a ver o encontro na diferença, mas problematizar justamente os modos como nos relacionarmos na educação, sobre qual olhar entendemos o diferir e como nos colocamos diante disso. Acreditamos que a diferença se trata de uma questão pedagógica necessária e que deve ser pensada fora dos discursos que tendem a uma homogeneização. Segundo Skliar (2015):

Las diferencias, así, se tornaram una questión pedagógica de prioridade, as veces condenadas a la óptica estrecha de uma relación binária exclusión/inclusión, normal/anormal, comum/especial - y otras veces seguiendo la perspectiva de un abordage especializado de indivíduos 
particulares al interior de las escuelas regulares. Em todos los casos, la pergunta que sobrevive es si las diferencias, así, en plural, fueram compreendidas en los escenários educativos según un lenguaje estrictamente pedagógico o, bien, si ese linguaje se ha visto afectado por discursos y dispositivos técnicos, jurídicos, morales, economicistas, politicistas, etcétera (p. 34).

Talvez este ensaio tenha sido isso: um exercício de uma linguagem pedagógica para pensarmos outros caminhos. Caminhos não únicos, não classificatórios, nem sempre harmônicos, mas caminhos que possam dar a ver o que há de singular e plural na relação, no exercício da docência, com crianças com cegueira, com as cartas, as conversações, com um coletivo, ao pesquisarescrever: encontros.

\section{REFERÊNCIAS}

BARROS, Laura Pozzana de; KATRUP, Vigínia. Cartografar é acompanhar processos. In. KASTRUP, Virgínia; PASSOS, Eduardo; ESCÓSSIA, Liliana da (orgs.). Pistas do método da cartografia: pesquisa-intervenção e produção de subjetividade. Porto Alegre: Sulina, 2009, p.52-75.

BIERCE, Ambrose. O dicionário do diabo. Tradução de Rogério W. Galindo, São Paulo: Editora Carambaia, 2016.

CHAPLIN, Charles. O Grande Ditador. Filme de Charles Chaplin. EUA, 1940. Disponível em: https://www.youtube.com/watch?v=-IV4t5onobY. Acesso em 22/04/2018.

DELEUZE, Gilles. Diferença e repetição. Rio de Janeiro: Graal, 2006.

DELEUZE, Gilles. O que é um dispositivo? In: DELEUZE, G. O mistério de Ariana. Lisboa: Veja, 1996, p. 83-96.

DELEUZE, Gilles; PARNET, Claire. Uma conversa, o que é? Para que é que serve? In: DELEUZE, Gilles; PARNET, Claire. Diálogos. Tradução de José Gabriel Cunha. Relógio d'Água Editores, Lisboa, 2004, p.12-47.

DIAS, Rosimeri Oliveira. Fragmentos de diário de campo, escrita e devir texto. In. RIBETTO, Anelice; CALLAI, Cristiana (orgs). Uma escrita acadêmica outra: Ensaios, experiências e invenções. Rio de Janeiro: Lamparina, 2016, p. 111-122.

FOUCAULT, Michel. Sobre a História da sexualidade. In: FOUCAULT, Michel. Microfísica do poder. Organização e tradução de Roberto Machado. Rio de Janeiro: Edições Graal, 1979. p. 243-276.

LARROSA, Jorge. Epílogo: A arte da conversa. In: SKLIAR, Carlos. Pedagogia (improvavél) da diferença: e se o outro não estivesse aí? Tradução Giane Lessa. Rio de Janeiro DP\&A, 2003, p.211-224. 
LARROSA, Jorge. A operação ensaio: sobre o ensaiar e o ensaiar-se no pensamento, na escrita e na vida. Revista Educação e Realidade. Porto Alegre, v.29, p.27-43, jan/jun. 2004.

LARROSA, Jorge. Prólogo: Uma experiência sensível com a palavra. In: SKLIAR, Carlos. Experiências com a palavra: notas sobre linguagem e diferença. Tradução de Giane Lessa. Rio de Janeiro: Wak Editora, 2012, p.7-9.

LARROSA, Jorge. Una lengua para la conversación. In. LARROSA, Jorge; SKLIAR, Carlos (Coordinadores). Entre Pedagogia y Literatura. Buenos Aires: Miño \& Dávila, 2013.

LISPECTOR, Clarice. Anonimato. In: Jornal do Brasil. Rio de Janeiro- 10/fev/1968 - p.2. Disponível em http://memoria.bn.br/DocReader/030015_08/111140. Acesso 03/08/2018.

NEVES, Claudia Abbês Baêta. Desejar. In: FONSECA, Tania Mara Galli; NASCIMENTO, Maria Lívia do; MARASCHIN, Cleci (orgs). Pesquisar na diferença: um abecedário. Porto Alegre: Sulina, 2015, p.69-72.

ORTEGA, Francisco. Amizade e estética em Foucault. Rio de Janeiro: editora Graal, 1999.

RIBETTO, Anelice. Experimentar a pesquisa em educação e ensaiar a sua escrita. Universidade Federal Fluminense (UFF) - Niterói, 2009. Disponível em: http://www.uff.br/pos_educacao/joomla/images/stories/Teses/TESE\%20ANELICE\%20RIBE TTO.pdf . Acesso em 24 de maio de 2019.

ROLNIK, Suely. Cartografia Sentimental: Transformações contemporâneas do desejo. Editora Estação Liberdade, São Paulo, 1989.

SKLIAR, Carlos. Experiências com a palavra: notas sobre linguagem e diferença. Tradução de Giane Lessa. Rio de Janeiro: Wak Editora, 2012.

SKLIAR, Carlos. La pronunciación de la diferencia entre lo filosófico, lo pedagógico y lo literário. Revista Pró-Posições, v. 26, n.1, p. 29-47, jan/abr. 2015. Disponível em: https://periodicos.sbu.unicamp.br/ojs/index.php/proposic/article/view/8642416Acesso em 05 de agosto de 2019.

SKLIAR, Carlos. Lo dicho, lo escrito, lo ignorado. Ensayos mínimos entre Educación, Filosofia y Literatura. Buenos Aires: Miño \& Dávila, 2011.

SKLIAR, Carlos. Pedagogia de las diferencias: notas, fragmentos, incertidumbres. Ciudad Autónoma de Buenos Aires: Centro de Publicaciones Educativas y Material Didático, 2017.

SKLIAR, Carlos. Pedagogia (improvavél) da diferença: e se o outro não estivesse aí? Tradução Giane Lessa. Rio de Janeiro DP\&A, 2003.

SKLIAR, Carlos; TÉLLEZ, Magaldy. Conmover la educación. Buenos Aires: Noveduc libros, 2017. 


\section{SOBRE AS AUTORAS:}

\section{Daiana Pilar Andrade de Freitas Silva}

Doutoranda do Programa de Pós-Graduação em Educação (PPGEDU) - Processos Formativos e Desigualdades Sociais - da Faculdade de Formação de Professores da Universidade do estado do Rio de Janeiro (FFP-UERJ). Professora de Ensino Básico Técnico e Tecnológico (EBTT) do Departamento de Educação do Instituto Benjamin Constant (DED-IBC). Participa do Grupo de Pesquisa e Estudos da Surdocegueira (GPESC), vinculado ao Centro de Estudos e Pesquisas do Instituto Benjamin Constant (CEPEQ). Faz parte do Coletivo Diferenças e Alteridade na Educação, vinculado ao Programa de Pós-Graduação em Educação - Processos Formativos e Desigualdades Sociais - da Faculdade de Formação de Professores da Universidade do Estado do Rio de Janeiro, que busca pensar, entre políticas, práticas e poéticas, como educadores, negociam cotidianamente os diferentes modos de ser e estar no mundo para se relacionar e trabalhar coletivamente numa perspectiva ética do encontro. E-mail: daianapilar@ hotmail.com (iD) http://orcid.org/0000-0002-7750-0324

\section{Anelice Ribetto}

Doutora em Educação pela Universidade Federal Fluminense (UFF). Professora Associada do Departamento de Educação da Faculdade do Formação de Professores da Universidade do Estado do Rio de Janeiro (UERJ/FFP/DEDU). É Coordenadora do Programa de Pós-Graduação em Educação (PPGEDU) - Processos Formativos e Desigualdades Sociais da Faculdade de Formação de Professores da Universidade do Estado do Rio de Janeiro (FFP-UERJ). Participa do Grupo de Pesquisa Vozes da Educação $(\mathrm{CNPq})$ e faz parte, na condição de coordenadora, do Coletivo Diferenças e Alteridade na Educação, que reúne professores da escola básica, professores e estudantes da Faculdade de Formação de Professores da Universidade do Estado do Rio de Janeiro, gestores das redes públicas de ensino e famílias de alunos ditos "pessoas com deficiências", para desenvolver projetos de pesquisa, de ensino e de extensão vinculados ao Departamento de Educação e ao Programa de Pós-Graduação em Educação, Processos Formativos e Desigualdades Sociais da Faculdade de Formação de Professores da Universidade do Estado do Rio de Janeiro. E-mail: anelatina@gmail.com

iD http://orcid.org/0000-0003-1097-4880

Recebido em: 18 de setembro de 2019

Aprovado em: 05 de novembro de 2019

Publicado em: 01 de janeiro de 2020 